\title{
Adjustment Disorder in Pregnant Women: Prevalence and Correlates in a Northern Mexican City
}

\author{
Cosme Alvarado-Esquivel ${ }^{\mathrm{a}, \mathrm{c}}$, Antonio Sifuentes-Alvarez ${ }^{\mathrm{a}, \mathrm{b}}$, \\ Carlos Salas-Martinez ${ }^{a}$, b
}

\begin{abstract}
Background: The epidemiology of adjustment disorder in pregnant women is largely unknown. We sought to determine the prevalence and correlates of adjustment disorder in pregnant women in Durango City, Mexico.

Methods: Pregnant women $(n=300)$ attending in a public hospital in Durango City, Mexico were studied. All enrolled pregnant women had a psychiatric interview to evaluate the presence of adjustment disorder using the DSM-IV criteria. A questionnaire was submitted to obtain general epidemiological data of the pregnant women studied. Bivariate and multivariate analyses were used to assess the association of adjustment disorder with the epidemiological data of the women studied.
\end{abstract}

Results: Fifteen $(5.0 \%)$ of the 300 women studied had adjustment disorder according to the DSM-IV criteria. Adjustment disorder was not associated with age, occupation, marital status, or education of pregnant women. In contrast, multivariate analysis of socio-demographic, clinical and psychosocial variables showed that adjustment disorder was associated with the variables lack of support from her couple (odds ratio $(\mathrm{OR})=3.83 ; 95 \%$ confidence interval $(\mathrm{CI}): 1.00$ - 14.63; $\mathrm{P}=0.04)$ and couple living abroad $(\mathrm{OR}=10.12 ; 95 \% \mathrm{CI}$ : 1.56 - 65.50; $\mathrm{P}=0.01)$.

Conclusions: This is the first report about the epidemiology of adjustment disorder in pregnant women in Mexico. Results provide evidence of the presence of adjustment disorder and contributing psychosocial factors associated with this disorder in pregnant women in Mexico. Results point towards further clinical and research attention should be given to this neglected disorder in pregnant women.

Keywords: Adjustment disorder; Pregnancy; Epidemiology; Mexico

Manuscript accepted for publication July 15, 2015

aBiomedical Research Laboratory, Faculty of Medicine and Nutrition, Juarez University of Durango State, Durango, Mexico

bMothers and Children's Hospital, Secretary of Health, Durango, Mexico

${ }^{\mathrm{c} C o r r e s p o n d i n g ~ A u t h o r: ~ C o s m e ~ A l v a r a d o-E s q u i v e l, ~ B i o m e d i c a l ~ R e s e a r c h ~}$ Laboratory, Faculty of Medicine and Nutrition, Juarez University of Durango State, Avenida Universidad S/N, 34000 Durango, Mexico.

Email: alvaradocosme@yahoo.com

doi: http://dx.doi.org/10.14740/jocmr2275w

\section{Introduction}

Adjustment disorder is a common diagnosis in a number of clinical settings including primary care, general medical practice [1], and psychiatric practice [2]. However, adjustment disorder has received little attention in research settings [1-4]. Instead, scientific attention has been focused on major depression [5]. Adjustment disorder is a constellation of stress-related conditions or significant distress that occurs in response to exposure to a distressing event [6]. Adjustment disorder carries a significant rate of morbidity [2]. A stressor is the cause of the adjustment disorder, and its diagnosis is based on the longitudinal course of symptoms in the context of the stressor [7]. Adjustment disorders have been classified under the trauma and stress-related disorders recently [3]. Adjustment disorders are found in all cultures and ages [7]. The prevalence of this disorder varies among groups. A $2.94 \%$ prevalence of adjustment disorder has been found in patients from primary healthcare centers in Catalonia, Spain [8]. Whereas a $12.5 \%$ prevalence has been reported in cancer patients [9]. A high prevalence $(36.5 \%)$ has been found in women referred to a consultation liaison psychiatric service because of positive scores on the Edinburgh postnatal depression scale in Queensland, Australia [10]. Treatment of adjustment disorders is psychotherapy [4, 11].

Very little is known about the epidemiology of adjustment disorders in pregnant women. To the best of our knowledge, there is not any report about the magnitude of these disorders in pregnant women in Mexico. Therefore, we sought to determine the prevalence and correlates of adjustment disorders in pregnant women in Durango City, Mexico.

\section{Materials and Methods}

Pregnant women studied and diagnosis of adjustment disorder

Three hundred pregnant women attending routine prenatal consultations in a public hospital (Mothers and Children's Hospital of the Secretary of Health) in Durango City, Mexico were enrolled in the study. Women were selected by random sampling from January to December 2013. Inclusion criteria 
Table 1. Socio-Demographic Characteristics of the Pregnant Women and Their Association With Adjustment Disorder

\begin{tabular}{|c|c|c|c|c|}
\hline \multirow{2}{*}{ Characteristics } & \multirow{2}{*}{ No. of women studied } & \multicolumn{2}{|c|}{ Adjustment disorder } & \multirow{2}{*}{ P value } \\
\hline & & No. & $\%$ & \\
\hline \multicolumn{5}{|l|}{ Age (years) } \\
\hline $13-17$ & 116 & 4 & 3.4 & 0.32 \\
\hline$>17$ & 184 & 11 & 6 & \\
\hline \multicolumn{5}{|l|}{ Occupation } \\
\hline Laborer & 19 & 1 & 5.3 & 1.00 \\
\hline Non-laborer & 281 & 14 & 5 & \\
\hline \multicolumn{5}{|l|}{ Marital status } \\
\hline Married & 91 & 3 & 3.3 & 0.44 \\
\hline Single & 48 & 5 & 10.4 & \\
\hline Divorced & 1 & 0 & 0 & \\
\hline Living together & 159 & 7 & 4.4 & \\
\hline Widowed & 1 & 0 & 0 & \\
\hline
\end{tabular}

Education (years)

$\begin{array}{llll}\text { None } & 1 & 0 & 0 \\ 1-6 \text { years } & 36 & 5 & 13.9 \\ 7-12 \text { years } & 251 & 9 & 3.6 \\ >12 \text { years } & 12 & 1 & 8.3\end{array}$

Birthplace

$\begin{array}{llll}\text { Durango State } & 299 & 15 & 5 \\ \text { Abroad } & 1 & 0 & 0\end{array}$

Residence place

$\begin{array}{lllll}\text { Durango State } & 297 & 15 & 5.1 & 1.00 \\ \text { Other Mexican State } & 3 & 0 & 0 & \end{array}$

Residence area

$\begin{array}{lllll}\text { Urban } & 249 & 10 & 4 & 0.22 \\ \text { Suburban } & 19 & 2 & 10.5 & \\ \text { Rural } & 32 & 3 & 9.4\end{array}$

Religion

$\begin{array}{lllll}\text { Yes } & 289 & 15 & 5.2 & 1.00 \\ \text { No } & 11 & 0 & 0 & \end{array}$

Health insurance

$\begin{array}{lllll}\text { Yes } & 297 & 15 & 5.1 & 1.00 \\ \text { No } & 3 & 0 & 0 & \end{array}$

Age at marriage

$\begin{array}{lllll}13-17 & 163 & 5 & 3.1 & 0.37 \\ >17 & 119 & 7 & 5.9 & \end{array}$

No. of marriages

$\begin{array}{lllll}\text { None } & 16 & 3 & 18.8 & 0.02 \\ \text { One } & 240 & 9 & 3.8 & \\ \text { More than one } & 44 & 3 & 6.8 & \end{array}$


for enrollment in the study were: 1) pregnant women within their 1 - 9 months of pregnancy; and 2) who voluntarily accepted to participate. Age, socioeconomic status, educational level, and occupation were not restrictive criteria for enrollment. All women had a psychiatric consultation during pregnancy and diagnosis of adjustment disorder was based on the DSM-IV criteria [12].

\section{Epidemiological characteristics of the pregnant women}

Socio-demographic, clinical and psychosocial characteristics of the participants were recorded in a questionnaire through a face-to-face interview (Supplementary 1, http://www.jocmr. org). Age, occupation, marital status, education, birthplace, residence, religion, having a health insurance, age at marriage, and number of marriages were obtained from all women studied. Clinical items included health status, obstetric history, gestational age, number of fetuses in the current pregnancy, fetal sex, and size and health status of the fetus. In addition, information about history of depression, stress or anxiety before or during pregnancy, smoking, consumption of alcohol, drug abuse, history of depression before pregnancy or trauma in life, history of complications during their last delivery, history of breastfeeding, health status of their last newborn, and number of children from all participants was obtained. Psychosocial items were: history of separation from parents at young age, presence of financial or family problems, bad relation with her mother in law, satisfaction with her education or body image, support from her couple, relatives, friends, colleagues or government, intended pregnancy, happiness for the sex of the fetus, bad relation with her couple, currently living with her couple, abandoned by her couple, violence from her couple, and couple living abroad.

\section{Statistical analysis}

Data were analyzed with the aid of the software SPSS version 15.0. The association between adjustment disorder and characteristics of the pregnant women was assessed by bivariate and multivariate analyses. We used the Pearson's Chi-square test and the Fisher exact test (when values were less than 5) for comparison of frequencies among groups. Multivariate analysis was performed only with variables with a $\mathrm{P}$ value equal to or less than 0.05 obtained in the bivariate analysis. Odd ratios (OR) and 95\% confidence intervals (CIs) were calculated by logistic regression using the Enter method. Statistical significance was set at a $\mathrm{P}$ value $<0.05$.

\section{Ethical aspects}

Participants were informed about the aims and procedures of the study and a written informed consent was obtained from all them. The Ethical Committee of the Mothers and Children's Hospital of the Secretary of Health in Durango City, Mexico approved this study.

\section{Results}

Pregnant women studied were $23.39 \pm 8.0$ years old (range 13 - 45 years). They were examined for adjustment disorder once within their 2 - 9 months (median: 7 months) of pregnancy. Of the 300 pregnant women studied, $126(42.0 \%)$ were primigravidae and $174(58.0 \%)$ were multigravidae (2 - 8 pregnancies).

Fifteen $(5.0 \%)$ of the 300 women studied had adjustment disorder according to the DSM-IV criteria. General socio-demographic characteristics of the pregnant women studied and their correlation with prevalence of adjustment disorder are shown in Table 1. The characteristic number of marriages was associated with adjustment disorder by bivariate analysis $(\mathrm{P}=$ 0.02). Other socio-demographic characteristics including age, occupation, marital status, education, birthplace, residence, religion, having a health insurance, and age at marriage did not show association with adjustment disorder $(\mathrm{P}<0.05)$.

Of the clinical characteristics of the pregnant women studied, the variables trauma in life and depression during pregnancy were associated with adjustment disorder by bivariate analysis. Other clinical characteristics including health status, obstetric history, gestational age, number of fetuses in the current pregnancy, fetal sex, size and health status of the fetus, history of stress or anxiety before or during pregnancy, smoking, consumption of alcohol, drug abuse, history of depression before pregnancy, history of complications during their last delivery, history of breastfeeding, health status of their last newborn, and number of children did not show association with adjustment disorder by bivariate analysis. Table 2 shows a correlation between a selection of clinical variables and prevalence of adjustment disorder in the pregnant women studied. Women with adjustment disorder were treated with psychotherapy.

With respect to psychosocial characteristics, the variables lack of support from her couple and couple living abroad were associated with adjustment disorder by bivariate analysis. Other psychosocial variables including history of separation from parents at young age, presence of financial or family problems, bad relation with her mother in law, satisfaction with her education or body image, support from her relatives, friends, colleagues or government, intended pregnancy, happiness for the sex of the fetus, bad relation with her couple, currently living with her couple, abandoned by her couple, and violence from her couple did not show association with adjustment disorder. A selection of psychosocial characteristics of the pregnant women studied and their association with prevalence of adjustment disorder is shown in Table 3.

Multivariate analysis of socio-demographic, clinical and psychosocial variables with $P$ values $<0.05$ obtained by bivariate analysis showed that adjustment disorder was only associated with the variables lack of support from her couple $(\mathrm{OR}=$ 3.83; 95\% CI: $1.00-14.63 ; \mathrm{P}=0.04)$ and couple living abroad $(\mathrm{OR}=10.12 ; 95 \% \mathrm{CI}: 1.56-65.50 ; \mathrm{P}=0.01)$. Table 4 shows results of the multivariate analysis.

\section{Discussion}

The epidemiology of adjustment disorder has been poorly 
Table 2. Results of the Bivariate Analysis of a Selection of Clinical Characteristics of the Pregnant Women and Their Association With Adjustment Disorder

\begin{tabular}{|c|c|c|c|c|}
\hline \multirow{2}{*}{ Characteristics } & \multirow{2}{*}{ No. of women studied } & \multicolumn{2}{|c|}{ Adjustment disorder } & \multirow{2}{*}{ P value } \\
\hline & & No. & $\%$ & \\
\hline \multicolumn{5}{|l|}{ Trimester of pregnancy } \\
\hline First & 16 & 0 & 0 & 0.41 \\
\hline Second & 87 & 3 & 3.4 & \\
\hline Third & 197 & 12 & 6.1 & \\
\hline \multicolumn{5}{|c|}{ Depression during pregnancy } \\
\hline Yes & 102 & 9 & 8.8 & 0.02 \\
\hline No & 198 & 6 & 3 & \\
\hline \multicolumn{5}{|l|}{ Stress during pregnancy } \\
\hline Yes & 135 & 9 & 6.7 & 0.23 \\
\hline No & 164 & 6 & 3.7 & \\
\hline \multicolumn{5}{|l|}{ Fetal health status } \\
\hline Healthy & 294 & 14 & 4.8 & 0.14 \\
\hline Ill & 3 & 1 & 33.3 & \\
\hline \multicolumn{5}{|c|}{ Outcome of last pregnancy } \\
\hline Delivery & 57 & 1 & 1.8 & 0.30 \\
\hline Cesarean section & 82 & 6 & 7.3 & \\
\hline Miscarriage & 3 & 0 & 0 & \\
\hline \multicolumn{5}{|c|}{ Health status of last newborn } \\
\hline Healthy & 132 & 6 & 4.5 & 0.30 \\
\hline Ill & 15 & 1 & 6.7 & \\
\hline Dead & 5 & 1 & 20 & \\
\hline \multicolumn{5}{|c|}{ Depression before pregnancy } \\
\hline Yes & 97 & 8 & 8.2 & 0.09 \\
\hline No & 202 & 7 & 3.5 & \\
\hline \multicolumn{5}{|l|}{ Trauma in life } \\
\hline Yes & 51 & 6 & 11.8 & 0.02 \\
\hline No & 248 & 9 & 3.6 & \\
\hline \multicolumn{5}{|l|}{ Stress before pregnancy } \\
\hline Yes & 102 & 7 & 6.9 & 0.28 \\
\hline No & 198 & 8 & 4 & \\
\hline
\end{tabular}

studied in Mexico in general, and there is a lack of information about the epidemiology of this disorder in pregnant women in this country in particular. The present study aimed to determine the prevalence and correlates of adjustment disorder in a sample of pregnant women in the northern Mexican city of Durango. We found a 5.0\% prevalence of adjustment disorder in the pregnant women studied. Comparison of the prevalence of adjustment disorder found in our study with those found in other studies can be hardly performed because there are only few studies about the prevalence of adjustment disorder in population groups reported in the medical literature. This fact is consistent with the reportedly poor attention that this disorder has received in research settings [1-4]. The prevalence of adjustment disorder found in pregnant women in our study is comparable with a $2.94 \%$ prevalence of adjustment disorder reported in patients from primary healthcare centers in Catalonia, Spain [8]. In contrast, the prevalence of adjustment disorder found in pregnant women in Durango City is lower than a $12.5 \%$ prevalence found in cancer patients in Leipzig, Germany [9]. Similarly, the prevalence found in our study is lower than a $36.5 \%$ prevalence found in women referred to a consultation liaison psychiatric service because of positive scores on the Edinburgh postnatal depression scale in Queensland, Australia [10]. The lower prevalence of adjustment disorder in pregnant women in our study than those reported in cancer patients and women referred to psychiatric service can be 
Table 3. Results of the Bivariate Analysis of a Selection of Psychosocial Characteristics of the Pregnant Women and Their Association With Adjustment Disorder

\begin{tabular}{|c|c|c|c|c|}
\hline \multirow{2}{*}{ Characteristics } & \multirow{2}{*}{ No. of women studied } & \multicolumn{2}{|c|}{ Adjustment disorder } & \multirow{2}{*}{ P value } \\
\hline & & No. & $\%$ & \\
\hline \multicolumn{5}{|c|}{ Separated from parents at young age } \\
\hline Yes & 94 & 7 & 7.4 & 0.25 \\
\hline No & 206 & 8 & 3.9 & \\
\hline \multicolumn{5}{|c|}{ Financial problems } \\
\hline Yes & 115 & 9 & 7.8 & 0.07 \\
\hline No & 185 & 6 & 3.2 & \\
\hline \multicolumn{5}{|l|}{ Family problems } \\
\hline Yes & 37 & 3 & 8.1 & 0.40 \\
\hline No & 263 & 12 & 4.6 & \\
\hline \multicolumn{5}{|c|}{ Satisfaction with educational level } \\
\hline Yes & 167 & 10 & 6 & 0.37 \\
\hline No & 133 & 5 & 3.8 & \\
\hline \multicolumn{5}{|c|}{ Support from her couple } \\
\hline Yes & 262 & 8 & 3.1 & 0.003 \\
\hline No & 37 & 6 & 16.2 & \\
\hline \multicolumn{5}{|c|}{ Desired pregnancy } \\
\hline Yes & 192 & 8 & 4.2 & 0.37 \\
\hline No & 108 & 7 & 6.5 & \\
\hline \multicolumn{5}{|c|}{ Relation with her couple } \\
\hline Good & 249 & 9 & 3.6 & 0.23 \\
\hline $\mathrm{Bad}$ & 48 & 4 & 8.3 & \\
\hline \multicolumn{5}{|c|}{ Living with her couple } \\
\hline Yes & 238 & 9 & 3.8 & 0.28 \\
\hline No & 57 & 4 & 7 & \\
\hline \multicolumn{5}{|c|}{ Ever abandoned by her couple } \\
\hline Yes & 91 & 6 & 6.6 & 0.22 \\
\hline No & 205 & 7 & 3.4 & \\
\hline \multicolumn{5}{|c|}{ Violence from her couple } \\
\hline Yes & 47 & 2 & 4.3 & 1.00 \\
\hline No & 249 & 11 & 4.4 & \\
\hline \multicolumn{5}{|c|}{ Couple living abroad } \\
\hline Yes & 8 & 2 & 25 & 0.04 \\
\hline No & 286 & 11 & 3.8 & \\
\hline
\end{tabular}

due to differences in health status among groups. We included mostly healthy women in our study whereas the other studies included ill participants or probably suffering from depression since they had positive scores for depression on the Edinburgh postnatal depression scale.

We searched for contributing factors associated with adjustment disorder in pregnant women and multivariate analysis showed that this disorder was associated with a lack of support from her couple and couple living abroad. To the best of our knowledge, this is the first report about the association of these factors with adjustment disorder. There is a lack of reports about contributing factors for adjustment disorder in pregnant women; therefore, we are unable to compare the contributing factors found in the present study with those in other studies.

The present study has a limitation; pregnant women studied were enrolled in one public hospital. The participating hospital attends mostly people of low socioeconomic level. Therefore, it is unclear whether pregnant women attending private hospitals or belonging to a medium or high socioeconomic level might have the same prevalence of adjustment dis- 
Table 4. Multivariate Analysis of Selected Characteristics of Pregnant Women and Their Association With Adjustment Disorder

\begin{tabular}{llll}
\hline Characteristic & Odds ratio & $\mathbf{9 5 \%}$ confidence interval & P value \\
\hline Number of marriages & 0.51 & $0.15-1.66$ & 0.26 \\
Trauma in life & 2.41 & $0.63-9.23$ & 0.19 \\
Depression during pregnancy & 1.00 & $0.26-3.84$ & 0.98 \\
Lack of support from her couple & 3.83 & $1.00-14.63$ & 0.04 \\
Couple living abroad & 10.12 & $1.56-65.50$ & 0.01 \\
\hline
\end{tabular}

order or the contributing factors as those found in the pregnant women studied.

\section{Conclusions}

This is the first report about the epidemiology of adjustment disorder in pregnant women in Mexico. Our results provide evidence of the presence of adjustment disorder and contributing psychosocial factors associated with this disorder in pregnant women in Durango, Mexico. Results point towards further clinical and research attention should be given to the adjustment disorder in pregnant women.

\section{Conflict of Interests}

None.

\section{References}

1. Casey P. Adult adjustment disorder: a review of its current diagnostic status. J Psychiatr Pract. 2001;7(1):32-40.

2. Patra BN, Sarkar S. Adjustment disorder: current diagnostic status. Indian J Psychol Med. 2013;35(1):4-9.

3. Casey P. Adjustment disorder: new developments. Curr Psychiatry Rep. 2014;16(6):451.

4. Carta MG, Balestrieri M, Murru A, Hardoy MC. Adjust- ment Disorder: epidemiology, diagnosis and treatment. Clin Pract Epidemiol Ment Health. 2009;5:15.

5. Casey P. The 'afterthought' diagnosis: rehabilitating adjustment disorders. Expert Rev Neurother. 2006;6(2):145151.

6. Akutsu PD, Abhari B. Adjustment disorders in Asians and Asian Americans. Asian J Psychiatr. 2014;7(1):68-70.

7. Casey P. Adjustment disorder: epidemiology, diagnosis and treatment. CNS Drugs. 2009;23(11):927-938.

8. Fernandez A, Mendive JM, Salvador-Carulla L, RubioValera M, Luciano JV, Pinto-Meza A, Haro JM, et al. Adjustment disorders in primary care: prevalence, recognition and use of services. Br J Psychiatry. 2012;201:137142.

9. Mehnert A, Vehling S, Scheffold K, Ladehoff N, Schon G, Wegscheider K, Heckl U, et al. [Prevalence of adjustment disorder, acute and posttraumatic stress disorders as well as somatoform disorders in cancer patients]. Psychother Psychosom Med Psychol. 2013;63(12):466-472.

10. Harvey ST, Pun PK. Analysis of positive Edinburgh depression scale referrals to a consultation liaison psychiatry service in a two-year period. Int J Ment Health Nurs. 2007;16(3):161-167.

11. Laugharne $J$, van der Watt G, Janca A. It is too early for adjusting the adjustment disorder category. Curr Opin Psychiatry. 2009;22(1):50-54.

12. American Psychiatric Association. Diagnostic and Statistical Manual of Mental Disorders: DSM-IV-TR, 4th ed. Washington, D.C. 2000. 